\title{
Kjøp og salg av organer
}

\author{
Kremmerne kommer: Vi bør åpne for salg av organer. Et strengt regulert organmarked kan sikre rettferdig \\ fordeling av organer og god behandling for donoren. Er det riktig?
}

ab Engelsk oversettelse av hele artikkelen på www.tidsskriftet.no

Det er et stort og stadig voksende behov for organer. Transplantasjon er vesentlig billigere enn dialysebehandling, og risikoen er sammenliknbar med keisersnitt, som jo er bredt akseptert. Det voksende behovet for organer er ikke blitt møtt med en tilsvarende vekst i tilgjengelige donorer, og det har vokst opp en illegal praksis som det er allmenn enighet om ikke er ønskelig. Et forslag for å øke tilgangen på organer har vært å åpne opp for kjøp og salg, og det er blitt ført vektige argumenter for at økonomiske incentiver er akseptabelt (1-6).

De som argumenterer for dette, mener at en strengt lovregulert organhandel er vesensforskjellig fra det illegale organmarkedet - her kan man sikre standarden på behandlingen og at organene fordeles på en rettferdig måte. Ved å prise organene opp mot en gjennomsnittlig årsinntekt, vil man også gjøre det interessant for alle og unngå at det bare vil være de fattigste som donerer. Strengt regulert organhandel kan også føre til at man unngår spenningene som kan oppstå dersom det innad i familien er sterke forventninger om at slektninger skal donere. Et annet argument for lovregulert organhandel er at levende anonym donasjon (som er tillatt i bl.a. Storbritannia og Sverige, men ikke i Norge) viser tydelig at det ikke bare er familiære og sosiale grunner til at folk donerer organer. Det understrekes derfor at når vi aksepterer andre incentiver, slik som sosiale og altruistiske motiver, så må også de økonomiske godtas (7).

\section{Seks spørsmål om kjøp og salg}

Det er derfor for lettvint å hevde at kommersialisering av organer nødvendigvis fører til utnyttelse - og at det er umoralsk (8). Av hensyn til trengende pasienter bør vi ta argumentene på alvor. Men bruk av økonomiske incentiver for å fremme organdonasjon reiser vanskelige spørsmål. Svarer argumentene for økonomiske incentiver på de grunnleggende utfordringene $\mathrm{og}$ på velfunderte motargumenter? Seks spørsmål, som ofte overses i debatten, krever svar.

Spørsmål 1. Virker incentivene? Det finnes lite konkret kunnskap om dette. Enkelte empiriske undersøkelser viser at økonomiske incentiver kan fungere (9), men at selgerne ofte er misfornøyd (10). Noen studier tyder på at incentiver er viktige for donasjon, men at de økonomiske betyr mindre enn andre incentiver (11).

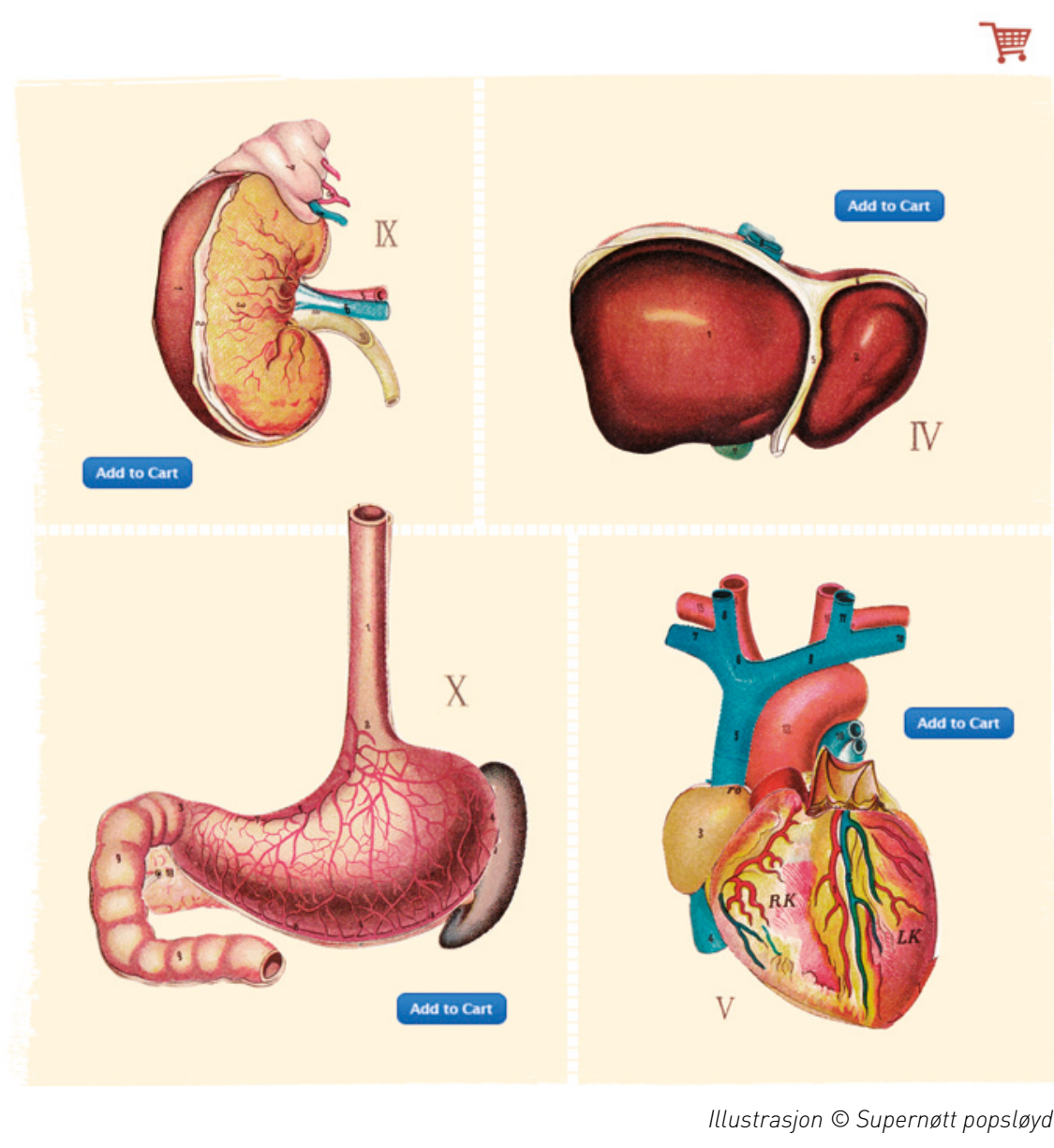

Spørsmål 2. Hva kan helsevesenet tillate seg å gjøre med friske mennesker? Organdonasjon (med levende giver) forutsetter medisinske inngrep på friske personer og bryter med et grunnleggende (hippokratisk) prinsipp: Primum non nocere. Det at helsepersonell kan gjøre ting med folk som ellers er forbudt (the medical exception) er blant annet basert på at det er nyttig for den enkelte. Unntak fra grunnleggende normer krever særskilt aktsomhet. Det er ikke åpenbart at (et økonomisk motivert) samtykke gir carte blanche for alle typer inngrep.

Spørsmål 3. Finnes det sosiale og kulturelle hindre for kommersialisering av organer? Europeiske undersøkelser viser at folk ser på organdonasjon som et sosialt og kulturelt fenomen, preget av gjensidighet i personlige relasjoner, som ikke ligger godt til rette for kommersialisering $(12,13)$. Faren for å miste folks tillit understrekes også av tilhengere av kommersialisering (6).

Spørsmål 4. Hvem eier organene i min kropp? Eierrettighetene til organer i «ens kropp» er uavklart. Vi kan eie ting og åndsverk (intellektuelle rettigheter), og jusen håndterer ting, handlinger og personer, men celler og organer er verken ting, åndsverk eller personer. Salg av organer vil derfor kreve juridisk nybrottsarbeid, og det er et grunnleggende filosofisk spørsmål om man kan selge hele eller deler av seg selv.

Spørsmål 5. Hva gjør det med en persons identitet å fjerne organer? Organer er mer enn ting, de konstituerer også den enkelte som person. Menneskelivet er gitt i og av et fellesskap og er ikke kjøpt. Det kan derfor ikke uten videre selges (14).

Spørsmål 6. Kan man som autonomt vesen bestemme seg for å redusere sin egen autonomi? Hvor mye av ens egen kropp kan man tillate seg å fjerne og fortsatt påberope seg moralsk status og selvbestemmelse? Vi tillater ikke folk å fjerne armer og bein om de måtte ønske det. Menneskets verdighet og rasjonalitet brukes ofte til å begrunne grenser for selvbestemmelsen over sin egen kropp (15), og den økono- 
miske rasjonaliteten synes å mangle slike grenser.

\section{Ikke overbevisende argumenter} Debatten om organsalg består av mange kategoriske røster: Enten er man prinsipielt for eller prinsipielt mot. Det nye nå er at man forsøker å se på alternativer som gjør det mulig å unngå erkjente ulemper, men beholde fordelene: Flere organer for å redde flere liv $(3-4,6-8)$.

Pasientene fortjener at vi reflekterer over de argumenter som begrunner vår praksis, så vi ikke blir overrasket over å oppdage at den mangler et overbevisende fundament - og at mange liv kunne vært reddet. Men så langt i debatten er jeg ikke overbevist: Det er langt fra klart at markedets usynlige hånd vil gi oss flere organer. Mange av de grunnleggende utfordringene ved organsalg er ikke håndtert (spørsmål 2-6). Dessuten finnes det en rekke effektive metoder for å øke tilgangen på organer (16): mediekampanjer, informasjonsarbeid overfor bestemte grupper og organisasjoner, undervisningsopplegg og samfunnsdebatt. Vi har hatt en (ensidig) underholdningsserie på TV (17), men mer kan åpenbart gjøres. Enn så lenge må vi brette opp ermene og stole på de synlige hender: Vi må informere, diskutere og fylle ut donorkort, og vi må være forsiktig med å legge press på familie og venner. Får vi det ikke til, kommer kremmerne.

\section{Bjørn M. Hofmann}

b.m.hofmann@medisin.uio.no

Senter for medisinsk etikk

Universitetet i Oslo

og

Seksjon for helse, teknologi og samfunn Høgskolen i Gjøvik

Bjørn Hofmann (f. 1964) er professor i medisinsk etikk ved Universitetet i Oslo og ved Høgskolen i Gjøvik. Han forsker og underviser innen medisinsk filosofi, vitenskapsteori og medisinsk etikk.

Ingen oppgitte interessekonflikter.

\section{Litteratur}

1. Kidney sale proposal sparks medical ethics debate. The Guardian, 3.8.2011. www. guardian.co.uk/society/2011/aug/03/kidney-saleproposal-medical-ethics (10.8.2011).

2. Jakobsen H. Bør åpne for salg av nyrer. www.forskning.no (16.8.2011).

3. Radcliffe-Richards J. Nephrarious goings on kidney sales and moral arguments. J Med Philos1996; 21: 375-416.

4. Harris J, Erin CA. An ethically defensible marke in organs. BMJ 2002: 325: 114-5.

5. Cherry MJ. Kidney for sale by owner: human organs, transplantation, and the market. Wash ington, D.C.: Georgetown University Press, 2005.

6. Omar F, Tinghög G. Welin S. Incentivizing deceased organ donation: a Swedish priority-setting perspective. Scand J Public Health 2011; 39 $156-63$.

7. Roff SR. We should consider paying kidney donors BMJ 2011: 343: d4867.

8. Lawlor R. Organ sales needn't be exploitative lbut it matters if they are). Bioethics 2011; 25: 250-9.
9. Heidary Rouchi A Mahdavi-Mazdeh M. Zamyadi M. Compensated living kidney donation in Iran: donor's attitude and short-term follow-up. Iran J Kidney Dis 2009; 3: 34-9.

10. Zargooshi J. Quality of life of Iranian kidney «donors». J Urol 2001; 166: 1790-9.

11. Bryce CL, Siminoff LA, Ubel PA et al. Do incentives matter? Providing benefits to families of organ donors. Am J Transplant 2005; 5: 2999-3008.

12. Schweda M, Schicktanz S. Public ideas and values concerning the commercialization of organ donation in four European countries. Soc Sci Med 2009; 68: 1129-36

13. Rid A, Bachmann LM, Wettstein V et al. Would you sell a kidney in a regulated kidney market? Results of an exploratory study. J Med Ethics 2009; 35: 558-64.

14. Leder D. Whose body? What body? The metaphysics of organ transplantation. I: Cherry MJ, red. Persons and their bodies: rights, responsibilities, relationships. Dordrecht: Kluwer Academic Publishers, 1999

15. Kerstein SJ. Autonomy, moral constraints, and markets in kidneys. J Med Philos 2009: 34: 573-85.

16. Siegel JT, Alvaro EM. Understanding organ donation. Applied behavioral science perspective. Chichester. West Sussex: Wiley Blackwell, 2010.

17. TV2. Livet på vent. 2011. www.tv2.no/ underholdning/livetpaavent/ (15.8.2011).

Mottatt 11.8. 2011, første revisjon innsendt 23.8. 2011, godkjent 22.9. 2011. Medisinsk redaktør Anne Kveim Lie. 